\title{
Nitrate import-export dynamics in groundwater interacting with surface-water in a wet-tropical environment
}

\author{
V. Rasiah ${ }^{\mathrm{A}, \mathrm{C}}$, J. D. Armour ${ }^{\mathrm{A}}$, A. L. Cogle ${ }^{\mathrm{A}}$, and S. K. Florentine ${ }^{\mathrm{B}}$ \\ A Department of Environment \& Resources Management, 28 Peters Street, PO Box 156, Mareeba, \\ Qld 4880, Australia. \\ ${ }^{B}$ Centre for Environmental Management, University of Ballarat, PO Box 663, Ballarat, Vic. 3350, Australia.

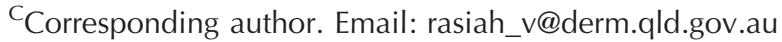

\section{Introduction}

Several studies (Koop et al. 2001; Brodie 2002; Baker 2003) from the north-east wet tropical coast of Australia have shown the health of the UN-listed, world heritage Great Barrier Reef (GBR) is being affected, at least partially, by high concentrations of nitrate in the reef lagoon. These workers have linked the high concentrations in the lagoon to the load carried in the major river systems which drain through the intensively cultivated agricultural catchments. The load estimations were based on the concentrations in major river systems after significant rainfall events in the catchments. However, other studies have shown that the N-load in the runoff was $<10 \mathrm{~kg} \mathrm{~N} /$ ha.year (Moody et al. 1996), compared with that in the fluctuating groundwater (GW), $40-110 \mathrm{~kg} \mathrm{~N} / \mathrm{ha}$ as nitrate-N (Rasiah et al. 2003a). It has also been reported that $30-130 \mathrm{~kg} /$ ha of nitrate-N was found to leach below the crop root-zone annually (Moody et al. 1996). This information suggests a nitrate hazard/risk in the GW, and this has not been included in the reported N-load estimates. The hazard/ risk needs clarification with regard to the links between the nitrate in: (i) leachate (LC) collected below crop root-zone and that in the GW, and (ii) GW and drain-water (DW).

Because most of the recharge that occurred during the rainy season was discharged between rainfall events and after the rains ceased (Cook et al. 2001; Rasiah et al. 2007), the latter workers speculated that the solutes, particularly the nitrate, in the GW were exported to streams via GW base-flow discharge. However, potential also exists for the nitrate leached below the crop root-zone to denitrify before entering $\mathrm{GW}$ and/or to be adsorbed in the soil matrix (Rasiah et al. 2003b). A better understanding of nitrate export from GW to surface water may help to improve the total N-loading estimates to the sensitive GBR lagoon, because the current loadings are based primarily on surface runoff (see above). In this context it should also be noted that a substantial proportion $(50-60 \%)$ of the total annual flow in the streams in this region is via GW base-flow discharge (Cook et al. 2001), which suggests the current Nloading may be underestimated.

It has been reported that in environments where a substantial proportion of the flow in streams, between rainfall events, after the rains ceased, and/or during the dry season was via GW baseflow discharge, the solutes in the GW were exported to surface waters (Hussain et al. 1999; Rutkowski et al. 1999; Burnett et al. 2003; Stieglitz 2005). Because even small fluxes of GW can deliver large quantities of solutes, particularly the ecologically/ environmentally sensitive nutrients, to surface water bodies (Johannes 1980; Moore 1999; Beaujouan et al. 2002), there 
is a need to quantify solutes in GW. The solutes exported via GW discharge in agricultural regions usually originate from fertilisers applied to intensive cropping systems, and the solutes that are of major environmental concern are nitrate and phosphate. The objectives of this study were to investigate whether any linkage existed between nitrate-N in (i) LC collected at $\sim 1 \mathrm{~m}$ depth under banana (Musa) and that in $\mathrm{GW}$, and (ii) GW and drain-water (DW); and to assess the hazard/risk of the concentrations against the trigger values proposed for the sustainable health of different aquatic ecosystems.

\section{Materials and methods}

\section{Study catchment}

The study was conducted in a large banana farm of $~ 300$ ha in the wet tropical Tully River Catchment $\left(17^{\circ} 30^{\prime} \mathrm{S}-18^{\circ} 30^{\prime} \mathrm{S}\right.$, $146^{\circ} \mathrm{E}$ ) in north-east Queensland, Australia. The major river systems in the catchment are the Tully River and Murray River, which discharge into the GBR lagoon. The climate is characterised by a very humid, summer rainy season and a mild, dry winter. The rainy season is from the middle of December through to May, with $>75 \%$ of the total mean annual rainfall of $4290 \mathrm{~mm}$ received during this period. The estimated pan evaporation rarely exceeds rainfall but irrigation may be required for some horticultural crops from July to November.

The topography ranges from precipitous mountains to depositional plains (Cannon et al. 1992). Only one soil of basaltic origin has been mapped out so far, although many of the fans are of mixed basaltic granitic origin. The land use in the catchment (as a percent of area) is undisturbed rainforest/sclerophyll (64\%), sugarcane (13\%), pasture $(18 \%)$, and bananas (3\%). Bananas occupy $\sim 5000$ ha, mainly adjacent to perennial streams for access to irrigation water during August-November; therefore, large plantations are on the Tully River levees. Bananas require well-drained soils without excessive flooding.

\section{Soil profile characteristics}

The soil type at the experimental site is brown Dermosol, characterised by high clay content, ranging from 62 to $68 \%$, with high anion exchange capacity, and the clay mineral is predominantly 1: 1 kaolinite (Gillman and Sinclair 1987). These soils were formed in situ from the metamorphic parent rocks that form the mountains in this area. Hydrogeological information is very scarce for this catchment; therefore, we provide below some basic information from the adjacent Johnstone River Catchment (JRC), which is similar to the study catchment with regard to hydrogeology, soils, and climate. The GW in the JRC basaltic regolith was generally found either at shallow depths $<15 \mathrm{~m}$ or at $>20 \mathrm{~m}-<40 \mathrm{~m}$ depth - the regional $\mathrm{GW}$ (Rasiah et al. 2007). The GW recharge was mainly from rainfall received during the wet season, 1500-2500 $\mathrm{mm}$ (midDecember-May), and most of the recharge was discharged as base-flow that occurred between major rainfall events and after the wet season (Rasiah et al. 2005, 2007). The saturated hydraulic conductivity in the basaltic profiles was relatively high, $5.1-17.1 \mathrm{~m} /$ day in the top $0-0.1 \mathrm{~m}$ and $0.14-0.27 \mathrm{~m} /$ day at
0.5-1.0 $\mathrm{m}$ depth, and the amount of rain water that percolated through the deep profiles was $>700 \mathrm{~mm} /$ year (Bonell et al. 1983; Cotching 1995).

\section{Lysimeters and leachate}

The custom-built lysimeter unit used in this study had 3 essential components: a container, ceramic cups, and vacuum tubing. The lysimeters were installed at $1 \mathrm{~m}$ below soil surface in boreholes excavated using a backhoe. Three lysimeters were installed in one row of a twin-row banana planting $\sim 1.5 \mathrm{~m}$ apart and another 3 lysimeters in the nearby interrow area at the same spacing. After the installation of each lysimeter, the soil was manually replaced in layers according to the original profile. The leachate was extracted under low and constant vacuum ( $\sim 150$ mbar) to simulate natural drainage at weekly intervals and more frequently as determined by rain events. After retrieval the samples were kept in an esky cooler until they were frozen at the laboratory that day. The samples remained frozen until analysis.

\section{Groundwater monitoring}

Soil boreholes (96 mm diam.) 10-11 $\mathrm{m}$ in depth were drilled using a hydraulic rig at 3 different locations in a triangular fashion in the banana paddock where the lysimeters were installed. The lysimeters were within the triangle. The distance between any 2 boreholes was $50 \mathrm{~m}$ and they were cased with sealed base PVC pipes ( $43 \mathrm{~mm}$ internal diam.). The bottom $3 \mathrm{~m}$ of the pipe was slotted and wrapped with a $250-\mu \mathrm{m}$ seamless polyester filter sock to prevent coarse sand particles entering the well. A $15-\mathrm{cm}$-thick bentonite collar layer was placed just above the slotted portion of the pipe to prevent water entry from above. The space between the pipe and the profile wall above the collar was back-filled tightly with sand and soil material to $4-5 \mathrm{~m}$ depth below soil surface. Above the back-filled layer, the space between the pipe and the soil profiles was filled with cement. Approximately $1 \mathrm{~m}$ of the pipe was above soil surface and the top end of the pipe was covered with a cap and locked. Bores cased in the aforementioned fashion are called piezometer wells or simply wells. The depth to GW (DGW) from the soil surface was measured manually using special tape and the measurements were carried out once in every 7-10-day interval from mid-December through to May in 2004, 2005, and 2006. These data along with ground elevation were used in the computation of the hydraulic head.

\section{Nitrate monitoring}

The GW samples for determination of oxides of nitrogen $\left(\mathrm{NO}_{\mathrm{x}}\right)$, which is predominantly nitrate-N, electrical conductivity (EC), and dissolved organic $\mathrm{C}$ (DOC) were collected when the DGW measurements were carried out. Water samples for chemical analysis were also collected from the main drain (DW) of the banana plantation at the same time as the GW sampling. We followed Alexander's (2000) procedure for GW sampling for chemical characterisation and the water samples from the wells at each sampling were taken in 3 appropriately cleaned $125-\mathrm{mL}$ PVC bottles. The DW samples were collected in a similar fashion from the main farm drain, which was $\sim 500 \mathrm{~m}$ (aerial distance) away from the experimental paddock, and the drain at the sampling location was $\sim 3 \mathrm{~m}$ deep. The samples were stored 
in the field and in the laboratory, and were analysed in a NATAaccredited laboratory.

\section{Cropping and fertiliser history}

The property was under rainforest before clearing for sugarcane production $\sim 70$ years ago. During the last 20 years the experimental paddock was under banana production and was in the second year after planting in 2004. The bananas were grown, after 1 year of grass fallow, for 4-5 years and received irrigation and fertigation during August-November depending on the rainfall. A drip system was used for irrigation and was scheduled to occur on evaporative demand. The potential evapotranspiration during the dry season was $6-7 \mathrm{~mm} /$ day. On average, the banana crop received fertiliser-N at $300-450 \mathrm{~kg} / \mathrm{ha}$. year. The rainfall data reported are from the Tully sugar mill and are considered to be similar to the experimental site.

\section{Statistical analysis}

The minimum, maximum, mean, lower and upper quartiles, coefficient of variation, and simple linear correlation analysis were determined for the data collected over the 3 year period, using the SAS (1991) software package.

\section{Results and discussion}

\section{Rainfall}

The monthly rainfall distribution during the investigation period, December-May in each year, varied substantially within and across years, and the large variabilities were supported by high CV (Table 1). Compared with the 117-year average, the 2005 season was drier, by $\sim 1000 \mathrm{~mm}$, whereas the 2004 season was wet. The 117-year monthly average shows the wettest months were February and March, followed by January, April, May, and December. The monthly distributions for 2004 and 2006 were generally similar to the long-term average. The largest daily rainfall distribution variation for a given month across the 3 seasons was observed for February, followed by December, March, May, January, and April.

\section{Leachate}

The mean analysis for LC collected under the rows and interrows of banana indicated no significant difference between the two (not shown); therefore, average values are reported (Table 2). The volume of LC collected increased with increasing amounts of the cumulative rainfall received during the 7-12 days before LC collection, and this trend was supported by the significant positive correlation between LC and rainfall. The total volume of
LC collected during the investigation period was $\sim 38 \%$ of the cumulative rainfall received before sampling and this agrees well with other reports for the neighbouring Johnstone River Catchment (Moody et al. 1996), and also agrees with the slope of the regression equation obtained in this study. However, only $66 \%$ of the variability in LC was accounted for by rainfall, implying that other unknown variable(s) controlled $34 \%$ of the variability. Nevertheless, we believe the total LC volume collected was less than the actual, because we missed several collections due to malfunctioning of the lysimeters. It was also possible that upslope lateral flow might have also contributed to the LC collected.

Because no LC was collected in 2004 and the number of collections in 2005 and 2006 were low compared with the GW, we emphasise the statistical analysis conducted on the data pooled across the 2 seasons. The large $\mathrm{CV}$ and the ranges for maximum and minimum ( $\max -\min )$ and upper and lower quartiles indicated substantial temporal variations in the LC collected.

Figure $1 b, c$ indicates that both nitrate and EC in the LC varied with time, increased with increasing volume of $\mathrm{LC}$ collected, and decreased with decreasing volume of LC. The significant positive association between a given chemical parameter and LC indicated that the solutes were leached out from the root-zone by the rain water that percolated through it (Table 3). The presence of the solutes in the LC suggests that there were stores of the chemicals in the root-zone for leaching or they were produced in the root-zone through decomposition, denitirification, desorption, or transported laterally from upslope, and/or deposited by rain. Regardless of the source, the concentrations might have been affected by the relative mobility of the solutes in the soil matrix and by anion exchange capacity (Gillman and Sinclair 1987; Rasiah et al. 2003b; Allred 2005), texture (Vinten et al. 1994; Chardon and Schoumans 2007), $\mathrm{pH}$ of the soil solution (Holford and Patrick 1979), rainfall intensity and amount and irrigation input (Yimprasert et al. 1976), biological processes (Johnson and Cole 1977), and relative anion concentration (Black and Waring 1976; Rasiah et al. 2003b). The nitrate-N in the total LC collected $(1248 \mathrm{~mm}$ ) was $90193 \mu \mathrm{g}$, implying that every $1 \mathrm{~mm}$ of water that percolated through the root-zone leached out $\sim 72 \mu \mathrm{g}$ of nitrate-N.

Lemola and Turtola (2000) reported that the $\mathrm{N}$ leached below the root-zone measured at field scale was $\sim 80 \%$ of that measured in the lysimeters, and they reported that the reason for the underestimation was unclear. These workers also showed that under-sowing reduced the $\mathrm{N}$ concentrations in runoff by $54 \%$,

Table 1. Monthly rainfall (mm) distributions in 2004, 2005, and 2006 for January-May and December compared with the long-term average from 1889 to 2005

$\mathrm{CV}$, Coefficient of variation; NA, not applicable

\begin{tabular}{lcccccrrr}
\hline & Dec. & Jan. & Feb. & Mar. & Apr. & May & CV (\%) & Total \\
\hline 2004 & 256 & 375 & 906 & 936 & 719 & 153 & 61 & 3345 \\
2005 & 93 & 510 & 127 & 352 & 605 & 62 & 80 \\
2006 & NA & 478 & 286 & 1209 & 795 & 228 & 68 \\
CV (\%) & 66 & 16 & 94 & 56 & 14 & 56 & 2996 \\
Av. (1889-2005) & 261 & 561 & 652 & 673 & 496 & 291 & NA & 36 \\
\hline
\end{tabular}


Table 2. Selected descriptive statistics to characterise temporal changes in leachate, groundwater, and drain-water (volume, $\mathrm{mm}$; hydraulic head, m) and the constituent solutes (nitrate-N and organic $\mathrm{C}, \mu \mathrm{g} / \mathrm{L} ; \mathrm{EC}, \mathrm{dS} / \mathrm{m}$ )

Min-max, Minimum and maximum; LQ-UQ, lower and upper quartiles; CV, coefficient of variation; $r$, correlation coefficient

\begin{tabular}{|c|c|c|c|c|}
\hline & Mean & Min-max & LQ-UQ & $\mathrm{CV}(\%)$ \\
\hline \multicolumn{5}{|c|}{ Leachate } \\
\hline \multicolumn{5}{|l|}{2005 (11) } \\
\hline Volume & $57 \pm 6$ & $7-73$ & $40-71$ & 38 \\
\hline Nitrate-N & $3518 \pm 448$ & $1060-6123$ & $2312-4460$ & 42 \\
\hline EC & $0.246 \pm 0.015$ & $0.189-0.363$ & $0.203-0.262$ & 20 \\
\hline \multicolumn{5}{|l|}{$2006(4)$} \\
\hline Volume & $68 \pm 1$ & 64-71 & $67-70$ & 4 \\
\hline Nitrate-N & $8586 \pm 2024$ & $3440-14358$ & 4875-11477 & 36 \\
\hline $\mathrm{EC}$ & $0.311 \pm 0.036$ & $0.185-0.382$ & $0.3021-0.378$ & 26 \\
\hline \multicolumn{5}{|c|}{ Data pooled across seasons } \\
\hline Volume & $60 \pm 3$ & $7-73$ & $57-71$ & 28 \\
\hline Nitrate-N & $5320 \pm 616$ & $1060-14358$ & $3440-55367$ & 58 \\
\hline $\mathrm{EC}$ & $0.276 \pm 0.010$ & $0.185-0.408$ & $0.231-0.304$ & 24 \\
\hline
\end{tabular}

Leachate volume $=0.38$ rainfall $(r=0.81, P<0.01)$

2004

Hydraulic head

Nitrate-N, groundwater

Nitrate-N, drain-water

Organic $\mathrm{C}$, groundwater

Organic C, drain-water

$\mathrm{EC}$, groundwater

EC, drain-water

2005

Hydraulic head

Nitrate-N, groundwater

Nitrate-N, drain-water

Organic $\mathrm{C}$, groundwater

Organic C, drain-water

$\mathrm{EC}$, groundwater

EC, drain-water

2006

Hydraulic head

Nitrate-N, groundwater

Nitrate-N, drain-water

Organic $\mathrm{C}$, groundwater

Organic C, drain-water

$\mathrm{EC}$, groundwater

EC, drain-water

Data pooled across seasons

Hydraulic head

Nitrate-N, groundwater

Nitrate-N, drain-water

Organic $\mathrm{C}$, groundwater

Organic C, drain-water

$\mathrm{EC}$, groundwater

EC, drain-water

Groundwater and drain-water

$\begin{array}{cr}16.65 \pm 0.16 & 15.69-18.94 \\ 3370 \pm 159 & 1760-4688 \\ 1402 \pm 381 & 96-4220 \\ 587 \pm 41 & 225-1000 \\ 2246 \pm 828 & 500-9100 \\ 0.091 \pm 0.03 & 0.077-0.114 \\ 0.113 \pm 0.01 & 0.046-0.192 \\ & \\ 16.86 \pm 0.14 & 15.23-18.54 \\ 3904 \pm 170 & 1973-4765 \\ 1982 \pm 247 & 244-4730 \\ 818 \pm 78 & 423-1905 \\ 1409 \pm 133 & 400-4000 \\ 0.089 \pm 0.01 & 0.057-0.205 \\ 0.094 \pm 0.02 & 0.054-0.124 \\ & \\ 17.60 \pm 0.16 & 16.10-18.67 \\ 5328 \pm 153 & 3254-5846 \\ 2560 \pm 335 & 25-5180 \\ 1011 \pm 35 & 750-1350 \\ 1814 \pm 175 & 600-3100 \\ 0.095 \pm 0.01 & 0.050-0.388 \\ 0.097 \pm 0.01 & 0.029-0.280 \\ & \\ 16.90 \pm 0.08 & 15.23-18.94 \\ 4135 \pm 109 & 1760-5846 \\ 1976 \pm 171 & 25-5180 \\ 7151 \pm 32 & 225-1905 \\ 1526 \pm 168 & 400-9100 \\ 0.088 \pm 0.01 & 0.050-0.205 \\ 0.095 \pm 0.01 & 0.029-0.280\end{array}$

$16.65 \pm 0.16$

$587 \pm 41$

$2246 \pm 828$

$.091 \pm 0.03$

$16.86 \pm 0.14$

$818+78$

$1409 \pm 133$

$0.089 \pm 0.01$

$17.60 \pm 0.16$

$1814 \pm 175$

$0.095 \pm 0.01$

$16.90 \pm 0.08$
15.69-18.94

$0-4688$

$25-1000$

$500-9100$

0.114

$5.23-18.54$

423-1905

$0.054-0.124$

$6.10-18.67$

-1350

$050-0.388$

$5.23-18.94$

$60-5846$

(25-1905

$.050-0.205$

$0.029-0.280$

$\begin{array}{cr}15.95-17.19 & 5 \\ 3038-3743 & 22 \\ 608-1720 & 98 \\ 475-725 & 32 \\ 600-1800 & 132 \\ 0.084-0.106 & 13 \\ 0.085-0.130 & 37\end{array}$

$16.60-17.31$

2926-4495 22

1000-3040 64

$529-1038 \quad 49$

$1003-1537 \quad 48$

$0.078-0.090 \quad 34$

0.084-0.105 17

$17.14-18.16 \quad 4$

5183-5743 13

1500-3560 57

$900-1150-16$

1500-2600 44

$0.082-0.090 \quad 66$

$0.080-0.110 \quad 47$

$16.41-17.46 \quad 5$

$3285-4810 \quad 25$

$741-3090 \quad 72$

$500-925$

$900-1744$

$0.080-0.091 \quad 21$

$0.082-0.109 \quad 38$

Hydraulic head $=16.761+0.006$ rainfall $(r=0.77, P<0.01)^{\mathrm{A}}$

${ }^{\mathrm{A}}$ Association between hydraulic head and cumulative rain received during 7-10 days before depth to groundwater was measured.

but the changes that occurred in the lysimeters were not known. Wivstad et al. (2005) reported that a change in climate to warmer conditions may increase leaching of $\mathrm{N}$, particularly outside the growing season, and suggested that measures should be undertaken to minimise $\mathrm{N}$ leaching during this period. The climate-change scenario is important for the wet tropics of Australia, because climate change models for this region indicate potential for high-intensity and large, infrequent rain events, suggesting rapid flushing out of solutes from crop rootzone and subsequently to GW.

The large standard errors for the means of nitrate-N and EC, ranges for max-min and upper and lower quartiles, and the high $\mathrm{CV}$ for the solutes indicated that within-season temporal variations were significant. The similar trend observed for the 

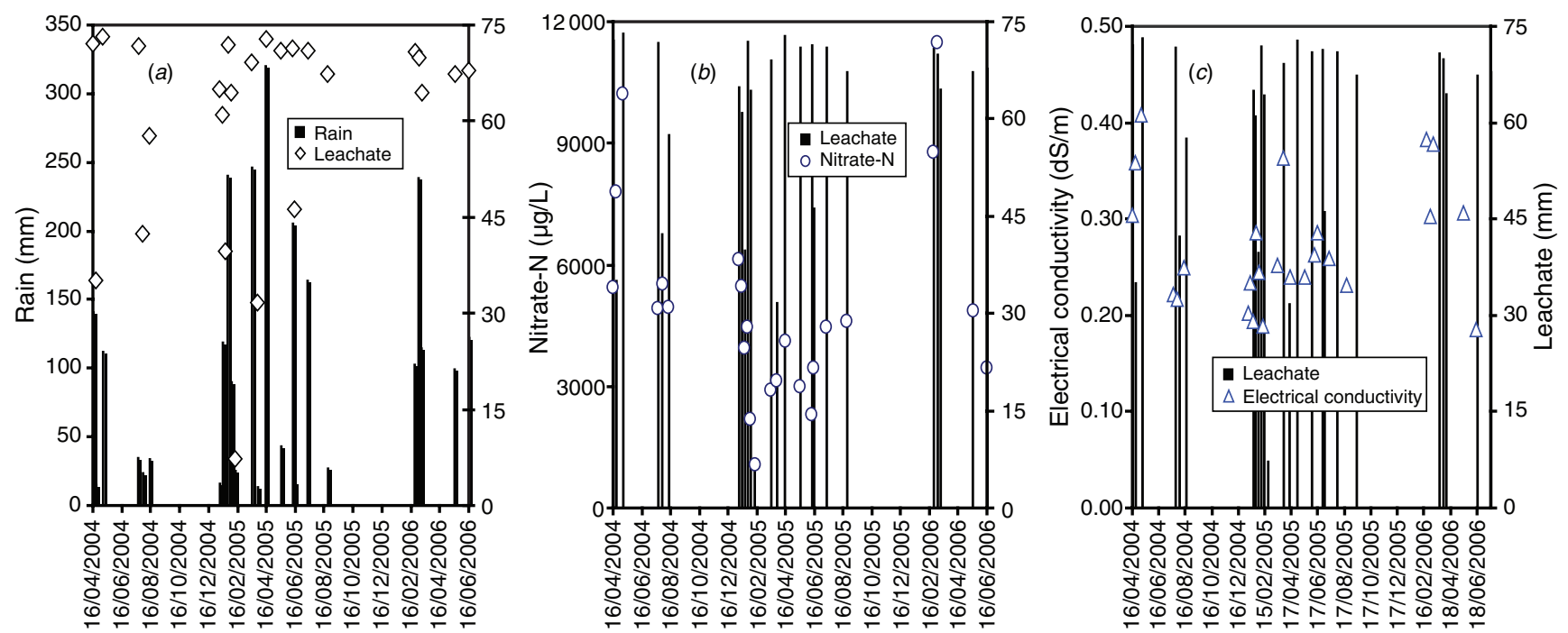

Fig. 1. (a) Impact of the rainfall distribution on the temporal behaviour of leachate, and influence of leachate on (b) nitrate-N and (c) electrical conductivity.

Table 3. Simple linear association between (i) leachate volume (LC) collected and concentration of solutes in it, (ii) concentration of given solute in LC and that in groundwater (GW), (iii) hydraulic head (HH) and concentration of solutes in it, and (iv) a given solute in $\mathrm{GW}$ and the corresponding solute in drain-water (DW)

Correlations in the table are significant at $P=0.05$, except that marked with

'†, which was significant at $P=0.10$; n.s., not significant at $P=0.10$

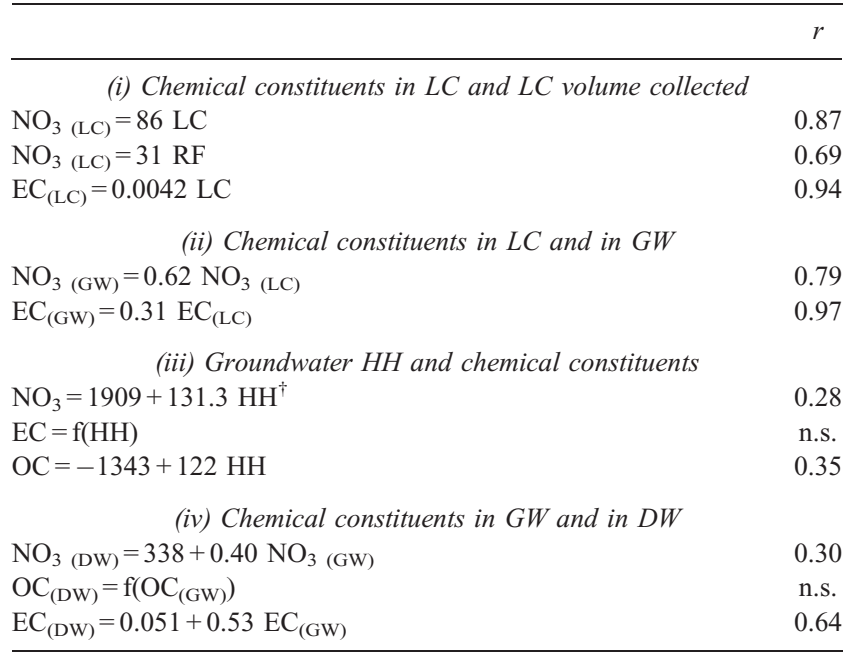

data pooled across seasons indicated significant differences in variations between seasons (Table 2). A comparison of the magnitudes of the statistical descriptors for the 2005 and 2006 seasons indicates the temporal variations were more rapid in 2006 than 2005. We suggest the reason for this was the higher rainfall received in 2006 than in 2005, and this led to $10 \mathrm{~mm}$ more LC in 2006 than in 2005, and consequently more solute leaching. The $\mathrm{CVs}$ for the chemical parameters were generally higher than the LC, suggesting that even small temporal changes in LC brought about relatively large temporal changes in the solutes. Discriminating the occurrence of solute peaks and troughs is important in order to reduce solute leaching to GW, particularly under supplementary irrigation practices, and to identify peak times and 'hot-spots' of leaching on undulating landscapes.

Usually the max-min values are used to characterise the magnitude of the variation or the dynamic nature of a dynamic variable during a given time period. However, the max-min are the extremes and their re-occurrence potential is low. On the other hand, values between the upper and lower quartiles represent $50 \%$ of the observations of a given variable, while excluding $25 \%$ of the values below the lower quartile and $25 \%$ above the upper quartile. Therefore, we believe the values between the upper and lower quartiles are better statistical descriptors to characterise the temporal variations of a given variable than the max-min values. Although other workers (Von Asmuth and Knotters 2004) have reported CV as a useful statistical parameter to characterise the temporal changes of a dynamic variable, we suggest that $\mathrm{CV}$ in conjunction with lower quartile and upper quartile is more useful than $\mathrm{CV}$ alone.

\section{Groundwater}

The data shown in Fig. $2 a$ indicate hydraulic head (HH), DGW, and hydraulic pressure (HP) varied with time within and between seasons. The HH is an indication of the amount of energy the GW possesses that can be utilised for flow, both vertically and laterally, provided a gradient of $\mathrm{HH}$ exists between 2 given points. We will therefore explore the temporal behaviour of flow potential using the $\mathrm{HH}$ data. The $\mathrm{HH}$ began to increase early in January, with the onset of rains, fluctuated (increased and decreased) during February-May, and thereafter decreased rapidly during May-June to pre January levels (Fig. 2a). The increases in HH were usually preceded by rainfall events and $\mathrm{HH}$ decreased between rainfall events. The significant positive correlation between $\mathrm{HH}$ and cumulative rainfall, received between 2 consecutive measurements, indicated the changes in $\mathrm{HH}$ were driven primarily by rainfall (Table 2). 

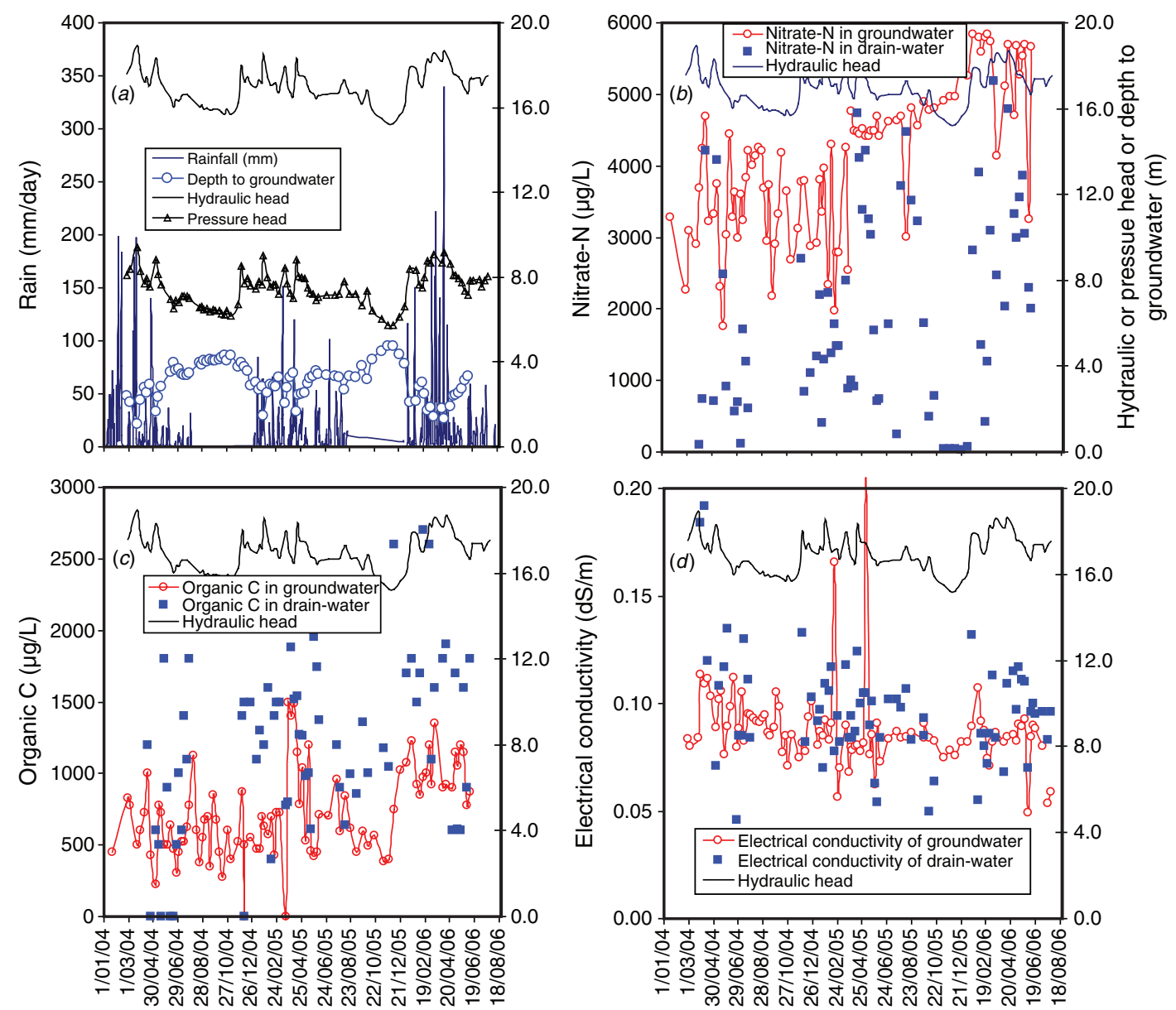

Fig. 2. Impact of rainfall distribution on hydraulic or pressure head and the depth to groundwater, and that of hydraulic head on the changes in groundwater chemistry.

The relationship between the rainfall and LC suggests the minimum LC collected, $7 \mathrm{~mm}$, would have required at least $18.4 \mathrm{~mm}$ of cumulative rain (Table 2). This would have resulted in the $\mathrm{HH}$ increasing by $\sim 11 \mathrm{~cm}$ and the water-table rising by $11 \mathrm{~cm}$. Another issue closely linked with the relationship between rainfall and LC is fertigation inputs during JulyDecember and the potential for nitrate leaching during this dry period. A single fertigation exceeding $18 \mathrm{~mm}$ would have provided the opportunity for nitrate leaching down to $\sim 1 \mathrm{~m}$; however, whether the leached nitrate would have reached the $\mathrm{GW}$ is questionable because the DGW after June was $>3.99 \mathrm{~m}$. Also, during July-December, the potential evapotranspiration was usually $6-7 \mathrm{~mm} /$ day; thus, the potential for leaching losses to occur seems to be low even with $30 \mathrm{~mm}$ irrigation input.

The energy available for flow, computed using difference between max-min or upper and lower quartile, could be utilised for vertical and/or lateral flow. However, in the presence of an aquitard in the regolith, the flows were more likely to occur laterally than vertically (Macpherson and Sophocleous 2004; Rasiah et al. 2007). The latter workers have provided evidence for the presence of an aquitard $>15-<40 \mathrm{~m}$ depth in the adjacent Johnstone River Catchment, which has similar geohydrological characteristics to the study catchment. Thus, we suggest the major proportion of the $\mathrm{HH}$ was utilised for lateral-flow discharge of GW into streams. Although we do not have tracer data to support the lateral-flow discharge hypothesis, there is evidence from the Atherton Catchment in this region (Cook et al. 2001). Further, the perennial flow in the farm main drain, even during the dry season July-December, is cited as visual evidence for the lateral-flow discharge hypothesis for this catchment.

The temporal trends exhibited by nitrate-N, DOC, and EC of the GW (Fig. $2 b-d$ ) are similar to HH. The increasing trends of the solutes with increasing $\mathrm{HH}$ are supported by the positive association between $\mathrm{HH}$ and $\mathrm{DOC}$ or nitrate (the latter significant only at $P=0.10$ ). Thus, we suggest the temporal changes in nitrate, EC, and DOC were driven by $\mathrm{HH}$ or GW fluctuations, which in turn were driven by the rainfall.

The mean, the ranges for max-min and upper-lower quartile, and the $\mathrm{CV}$ for the solutes were again used to characterise the temporal behaviour, and the values for these statistical parameters indicated significant temporal variations (Table 2). Higher values for these parameters of the solutes than $\mathrm{HH}$ indicated that the temporal changes in the solutes were more rapid than $\mathrm{HH}$. The significant difference in nitrate concentrations between seasons is considered as the indirect 
influence of seasonal rainfall differences on nitrate import to GW and also the positive association between $\mathrm{HH}$ and nitrate (Tables 2 and 3). The mean nitrate for the driest season (2005) was higher than wettest (2004), whereas we anticipated it to be the opposite and we are not in a position to offer an explanation for this contradiction.

The difference between the max-min data indicated potential existed for 2928,1792 , and $2592 \mu \mathrm{g} / \mathrm{L}$ of nitrate-N, respectively, in 2004, 2005, and 2006 to be transported laterally/vertically and/or to have undergone biochemical reactions. The biochemical reactions might have been denitrification and/or adsorption in the soil matrix. There is little or no evidence from this region to support significant denitrification in the soil matrix, but adsorption was possible because of the high anion exchange capacity of these soils (Rasiah et al. 2003b). The likelihood of transport to the deep GW systems was low, as other workers have shown the concentrations to decrease with increasing well depth (Parker et al. 1991; Rasiah et al. 2005). Thus, we suggest a major proportion of the nitrate was exported to streams via $\mathrm{GW}$ base-flow discharge.

We tested the sensitivity of the functional relationship between $\mathrm{HH}$ and nitrate-N in GW (Table 3), using the mean $\mathrm{HH}$ obtained from the data pooled across the 3 seasons, and it predicted the mean nitrate- $\mathrm{N}$ as $4123 \mu \mathrm{g} / \mathrm{L}$, which agreed well with the corresponding data (Table 2). However, the smallest change in $\mathrm{HH}(0.11 \mathrm{~m})$ predicted the nitrate-N as $1920 \mu \mathrm{g} / \mathrm{L}$, compared with the observed value of $1760 \mu \mathrm{g} / \mathrm{L}$, suggesting the predictive ability was poor at low $\mathrm{HH}$ but this predictive ability is satisfactory given the correlation coefficient of 0.28 for the equation at $P=0.10$. The nitrate concentrations in conjunction DOC need to be considered, as potential existed for aerobic and/ or anaerobic bio-utilisation of both DOC and nitrate in the soil matrix. However, $\mathrm{C}: \mathrm{N}$ ratios suggest that the potential for the bio-utilisation was low, because the $\mathrm{C}: \mathrm{N}$ were usually much less than the optimum $10: 1$.

The base-flow discharge of $>50 \%$ reported for this region (Cook et al. 2001; Rasiah et al. 2007), in conjunction with the high nitrate found in the GW, suggests that strategies need to be developed to reduce the export of nitrate from GW to streams. However, the water management options available are limited, because the nitrate import into the $\mathrm{GW}$ and its export to streams are controlled by rainfall received, 2500-3000 $\mathrm{mm}$, during the wet season (Table 1). The irrigation input, if any, was only during August-December, and the leaching of solutes to depths $>1 \mathrm{~m}$ and the transport to the GW are believed to be low during this period. The irrigation system used (drip system), irrigation practices followed (depending on evaporative demand), and the high costs involved with over-irrigation were not conducive for substantial leaching losses below the root-zone. However, potential existed for any unused/underutilised fertiliser- $\mathrm{N}$ in the root-zone to be transported to the GW with the onset of rains in December-January. This claim is supported by the largest nitrate, DOC, and EC peaks being observed in January (Fig. $2 b-d$ ). The other options available for growers to reduce nitrate import to $\mathrm{GW}$ and the subsequent export to streams are incorporation of riparian buffers between the crops and streams (for sugarcane and banana), interrow grasscovers (for banana), reducing fertiliser- $\mathrm{N}$ input or increasing crop uptake of $\mathrm{N}$, and the use of a nitrogen scavenger grass or other grasses/crops during the fallow period of both sugarcane and banana systems.

Riparian buffers are not widely incorporated in this catchment as there is insufficient information available on the most effective type of buffer, their maintenance and management, and the cost-effective width of the buffers required. Preliminary studies have shown interrow grasscovers were very effective in reducing wheel traffic-induced compaction in this catchment (Rasiah et al. 2009), but their effectiveness in mining the unused/underutilised fertiliser- $\mathrm{N}$ are not known. However, high infiltration under interrow grasscovers (Rasiah et al. 2009) can provide conditions favourable for increased import of solutes to GW and consequently the export to streams later.

There has been a substantial reduction in $\mathrm{N}$-fertiliser use during the last 5-6 years due to the efforts of researchers and growers, and the input has decreased from 600-700 to $300-400 \mathrm{~kg} \mathrm{~N} /$ ha.year for banana (authors' personal experience). We are not aware of any current studies to increase crop uptake of $\mathrm{N}$ when excessive amounts are available in soil profiles. There have been no systematic research efforts in this region with regard to nitrogen scavenger-grass studies during the fallow period after the banana crop. The banana crop phase usually lasts $4-5$ years, and after that the paddocks are fallowed for 12-18 months before planting the next crop. During the fallow phase the paddocks are left idle with grasses and weeds, but there have been demonstration studies to include soybeans during the fallow phase of sugarcane (authors' personal experience). These demonstrations have shown substantial plant residue organic- $\mathrm{N}$ in soils instead of $\mathrm{N}$ scavenging. The plant residue organic-N was estimated to range from 80 to $140 \mathrm{~kg} \mathrm{~N} /$ ha.year, but its temporal release pattern during the sugarcane crop-phase and/or its utilisation by the crop have not been well established.

The aforementioned management options at farm level should be considered during cropping/farming systems initiatives. We suggest that growers should be permitted flexibility, with no imposed solutions. In addition, cost effectiveness should be given priority for any management option to succeed. Insufficient information may be currently available for growers to select management options appropriate for them. Further, actions to reduce N-loading via the GW baseflow discharge may have to consider farm level soil information with regard to leaching characteristics (clayey $v$. loamy $v$. sandy soils) and focus on areas that contribute most to the loading, i.e. site-specific hot-spots rather than blanket recommendations.

\section{Associations between the solutes in the leachate and groundwater}

Significant positive associations existed between the solutes in the LC and GW, suggesting the solutes leached out from the root-zone were transported to the GW. However, we do not have tracer data to conclusively support the claim. The slope for the nitrate association indicates $\sim 62 \%$ of the nitrate in the LC was transported to the GW. Although the GW chemistry at a given location cannot be linked directly to that of the LC at another location, the regression in general indicates an indirect cause-effect relationship. Other variables might have also 
controlled the transport of nitrate from the LC to GW, including adsorption/desorption reactions, denitrification, the time-lag for transport from the lysimeter to $\mathrm{GW}$, and the upslope lateral transport of nitrate into the piezometer wells.

\section{Chemistry of drain-water}

Drain-water nitrate, DOC, and EC (Fig. 2b-d) showed temporal behaviour similar to those in GW. A comparison of the CVs for the solutes in DW and GW indicated that the solute concentrations in the DW changed more rapidly than the GW (Table 2). A comparison of the means, min-max, and lower-upper quartiles for nitrate in GW and DW indicated the concentrations were usually higher in the GW (Table 2), suggesting the existence of a concentration gradient from the GW to DW. However, similar comparisons for EC and DOC indicated reverse trends. We suggest at least 2 reasons for these anomalies. First, the higher DOC in DW was partially due to input from surface runoff into the drain and the runoff usually carried higher DOC than GW. Second, the nitrate in surface runoff was usually low compared with that in the GW (Moody et al. 1996; Rasiah et al. 2003a, 2005).

\section{Associations between the solutes in groundwater and drain-water}

Significant positive associations existed between the solutes in the GW and DW (Table 3). These associations suggest that $40 \%$ of the nitrate in the GW was linked to that in the DW and $53 \%$ of the total ions (EC). The reasons provided for the low nitrate in GW compared with LC are again cited here for the low nitrate in DW $v$. GW along with a dilution effect in the drain. Other studies
(Cook et al. 2001; Rasiah et al. 2007) show the major proportion of the recharge that occurred during the rainy season in this region was discharged, as lateral base-flow discharge, between rainfall events and after the rains ceased, and this discharge contributed to $\sim 60 \%$ of the total annual flow in perennial streams. The latter information in conjunction with the statistical associations between the solutes in the GW and DW and the slope/gradients suggest the potential for the export of solutes, including nitrate, in the GW to streams via GW lateral flow discharge.

\section{Concomitancy of temporal changes}

The data in Fig. 3 indicate concomitant increases or decreases in nitrate- $\mathrm{N}$ concentration in the 3 compartments (LC, GW, and DW). We believe this behaviour is theoretically and physically impossible, because there should have been a lag-time in the transport from one compartment to the one immediately below it. Generally, lag-time information at field scale is unknown and complex, requiring studies involving the use of tracers, automated loggers and samplers, and very frequent sampling, and these were beyond the financial scope of this study. The complexities involved with regard to the changes in nitrate concentration from one compartment to another are attributed to reasons provided elsewhere in the text. Furthermore, in this study the water samples from the 3 compartments were collected on the same day; thus, it is very likely that the transport lag-time factor between 2 consecutive compartments was not accounted for by the sampling schedule. We believe very short, frequent sampling intervals might have picked up the lag-time impact. Because the transport processes within the soil matrix are temporally dynamic, may be even at second intervals, this

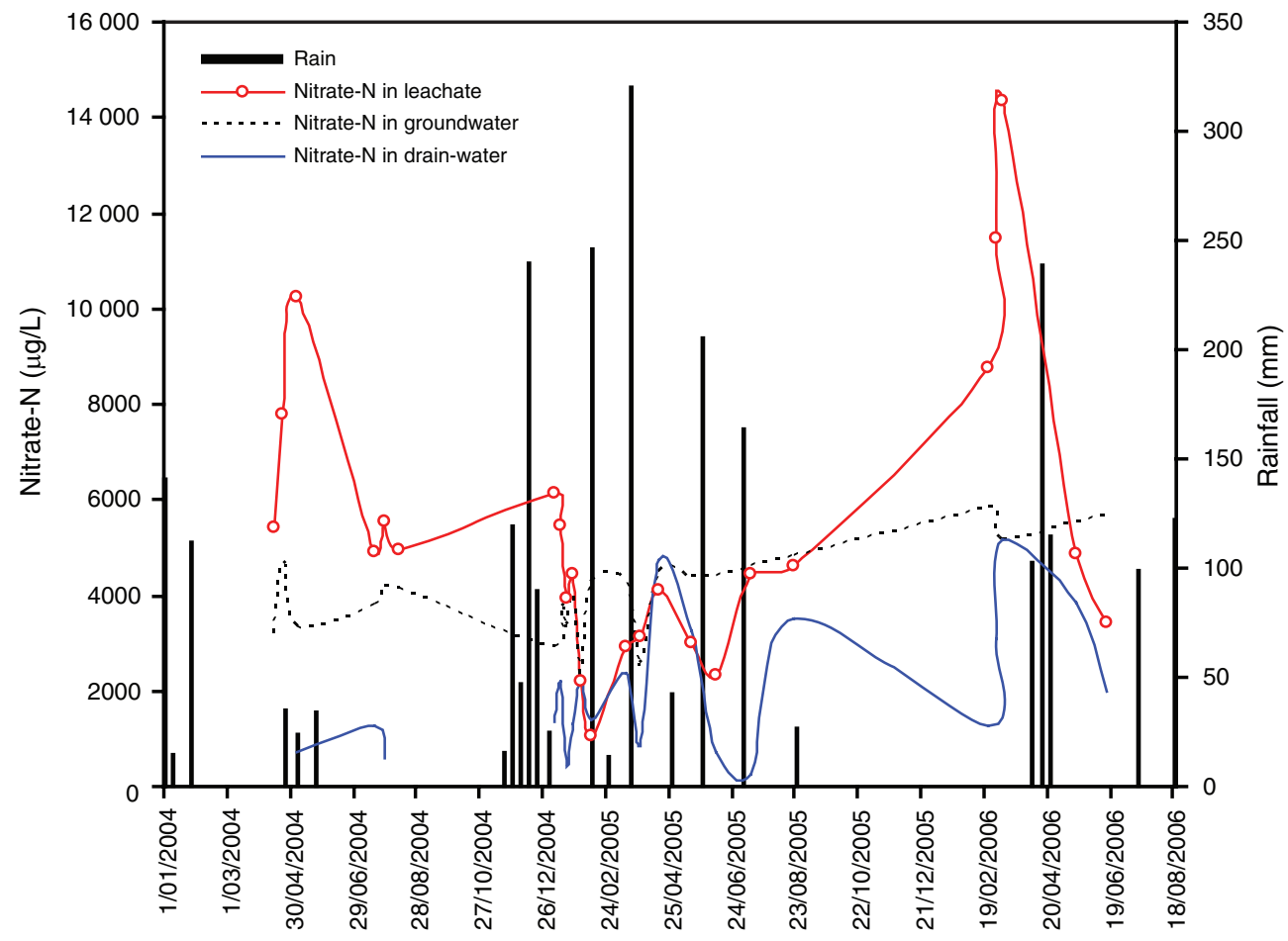

Fig. 3. Temporal changes of the nitrate- $\mathrm{N}$ in leachate, groundwater, and drain-water. 
raises the issue of how short intervals should be to resolve the concomitant increasing/decreasing trends.

The CVs for the nitrate in LC, GW, and DW (Fig. 3) indicate the variations were most rapid in DW, followed by LC and GW (Table 2). Similar trends were observed for the other solutes, DOC and EC, indicating the variations were consistent. Thus, we suggest the following for the differences in CVs (rapid, slow, etc.) among the different compartments. First, the more rapid changes of the solutes in DW compared with those in LC or GW are attributed to the differences in sources from which they were derived. The solutes in DW were transported from surface and subsurface sources, unlike those in the LC and GW which were primarily subsurface in origin. Second, the higher CVs for the solutes in LC than GW are attributed to the relatively short transport distance between the soil surface and lysimeter cups ( $1 \mathrm{~m}$ ) of LC compared with 2-4 m from the cups to the depth to GW. If the primary driver of the changes in solutes within a given season was the rainfall distribution and total, then the changes would have been largest in 2004, followed by 2005 and 2006, respectively. However, the CVs for the nitrate suggest this was not the case, except in 2004 (Tables 1 and 2). This suggests temporal changes were also controlled by other factors, particularly in GW, such as adsorption/desorption reactions.

\section{Implications of the nitrate in groundwater to aquatic ecosystem health}

The guideline trigger values for the sustainable health of different aquatic ecosystems in north-east Queensland for oxides of $\mathrm{N}$, which is predominantly nitrate- $\mathrm{N}$, are provided in table 3.3.4 of the ANZECC, ARMCANZ (2000) National Water Quality Management strategy report. The trigger value ranges are $1-4 \mu \mathrm{g} / \mathrm{L}$ for the offshore marine reef, $2-8 \mu \mathrm{g} / \mathrm{L}$ for the inshore marine reef, $10 \mu \mathrm{g} / \mathrm{L}$ for the lowland rivers, freshwater lakes, reservoirs, and wetlands, and $30 \mu \mathrm{g} / \mathrm{L}$ for the upland rivers and estuaries. Trigger values have not been provided for nitrate in GW, because information about its export processes and the load carried in the dischargeable water is scarce.

The min-max, $25-5180 \mu \mathrm{g} / \mathrm{L}$, for nitrate-N in DW indicates that it has exceeded the trigger values for the health and sustainability of most of the aquatic ecosystems. The minimum $25 \mu \mathrm{g} / \mathrm{L}$ was observed only once during the 3 seasons and most of the values were $>100 \mu \mathrm{g} / \mathrm{L}$. As indicated elsewhere in the text, we chose the values between the lower and upper quartile, $741-3090 \mu \mathrm{g} / \mathrm{L}$, in order to increase the confidence for risk assessment. This consideration indicates that $45(50 \%)$ out of the 90 values were $1-2$ orders of magnitude higher than the trigger values. If we also include the values greater than the upper quartile $(75 \%)$, then the risk was 68 values out 90, suggesting the risk associated with the export of nitrate in GW is high.

We have shown that the nitrate in the GW contributed (40\%) substantially towards that in the DW; therefore, we excluded the contribution by other sources $(60 \%)$ and recomputed the lower-upper quartile, $296-1237 \mu \mathrm{g} / \mathrm{L}$, for the nitrate- $\mathrm{N}$ in the DW that was linked to the GW only and found the values within range were still orders of magnitude higher than the trigger values. Though it is well known there will be a substantial dilution effect along the transport pathway from the drain to major rivers that discharge into the reef, the proportional contribution of the nitrate- $\mathrm{N}$ in the $\mathrm{GW}$ towards the total in the major river systems may remain more or less unaltered. It should also be noted it is difficult if not impossible to estimate the dilution factor from the $\mathrm{GW}$ to the river systems.

\section{Conclusions}

Our results show that $\sim 38 \%(1000 \mathrm{~mm})$ of the rainfall received during a given season $(2700 \mathrm{~mm})$ percolated to depth $>1 \mathrm{~m}$ of the soil profile. The volume of the LC collected between 2 consecutive measurements depended primarily on the cumulative rainfall received in this period; however, we believe the total LC collected was an underestimate. Every millimetre of the water that percolated through the top $1 \mathrm{~m}$ of the soil profile leached out $86 \mu \mathrm{g}$ of nitrate-N from the banana root-zone. Approximately $62 \%$ of the nitrate- $\mathrm{N}$ that leached below the root-zone was exported to the GW, and the amounts imported were driven by high hydraulic heads, which increased with increasing rainfall. This implies the rainfall-driven changes in $\mathrm{HH}$ were primarily responsible for the changes in nitrate concentration in the GW. Approximately $40 \%$ of the nitrate-N in the GW was exported to the drain via GW base-flow discharge; however, dilution in the DW might have underestimated the real export from GW to DW. The nitrate-N concentration gradient in the $\mathrm{LC}>\mathrm{GW}>\mathrm{DW}$ direction indicates increasing dilution effect and/or other pathways of nitrate losses from GW to DW. The temporal changes of nitrate were most rapid in the DW followed by LC and GW. This suggests that nitrate export to sensitive terrestrial aquatic ecosystems could be undertaken by monitoring the streams only. However, the monitoring should be undertaken not only after major rainfall events, but also between rainfall events and immediately after rains cease. We believe this is one among the few studies that have statistically demonstrated the 3-way linkage, at field scale, of the nitrate in the LC, GW, and DW. In future, this less expensive (without the use of tracers) exercise could be undertaken at frequent samplings to resolve the concomitant increases/decreases in the 3 compartments in other intensively fertilised agricultural catchments. This study provides mathematical support for the transport of near sub-surface sourced nitrate to streams via GW base-flow discharge.

\section{Acknowledgments}

The authors gratefully acknowledge the financial support provided by the Cooperative Research Centre for Catchment to Reef, for the field and laboratory support provided by Messrs HD Heiner and D Dwyer and Mss $\mathrm{T}$ Whiteing and DE Rowan, the growers who participated in the research, and the internal review and editorial comments provided by Drs Bob Noble and Chris Carroll, and Ms Glynis Orr.

\section{References}

Alexander DG (2000) 'Hydrographic procedure for water quality sampling. Water monitoring Group, Water Resource Information \& Systems Management.' (Department of Natural Resources: Brisbane, Qld)

Allred BJ (2005) Nitrate mobility in unsaturated soil affected by the presence of different clay mineral types. American Geophysical Union, Spring Meeting, Abstract \# H43B-10. 
ANZECC, ARMCANZ (2000) 'Australian and New Zealand guidelines for fresh and marine water quality 2000, No. 4.' National Water Quality Management Strategy. (Australian and New Zealand Environment and Conservation Council, and Agriculture and Resource Management Council of Australia and New Zealand: Canberra, ACT)

Baker J (2003) 'Report on the study of land-sourced pollutants and their impacts on water quality in and adjacent to the Great Barrier Reef.' (Department of Primary Industries: Brisbane, Qld)

Beaujouan V, Durand P, Ruiz L, Aurousseaeau P, Cotteret G (2002) A hydrological model dedicated to topography-based simulation of nitrogen transfer and transformation: rationale and application to the geomorphology-denitrification relationship. Journal of Hydrological Processes 16, 493-507. doi:10.1002/hyp.327

Black AS, Waring SA (1976) Nitrate leaching and adsorption in Krasnozem from Redland Bay. Qld. III. Effect of nitrate concentration and adsorption and movement in soil columns. Australian Journal of Soil Research 14, 189-195. doi:10.1071/SR9760189

Bonell M, Gilmour DA, Cassells DS (1983) A preliminary survey of the hydraulic properties of the rainforest soils in the tropical North-East Queensland and their implications for the runoff process. Catena $\mathbf{4}$, $57-78$.

Brodie J (2002) The effects of landuse on water quality in Australian northeast coastal catchments and coastal waterways. Australian Centre for Tropical Freshwater Research (ACTFR), James Cook University, Townsville, Report No. 02/07.

Burnett WC, Bokuniewicz H, Huettel M, Moore WS, Taniguchi M (2003) Groundwater and pore water inputs to the coastal zone. Biogeochemistry 66, 3-33. doi:10.1023/B:BIOG.0000006066.21240.53

Cannon MG, Smith CD, Murtha GG (1992) Soils of the Cardwel-Tully area, North Queensland. Division of Soils Divisional Report No. 155, CSIRO, Australia.

Chardon WJ, Schoumans OF (2007) Soil texture effects on the transport of phosphorus from agricultural land in river deltas of Northern Belgium, The Netherland and North-West Germany. Soil Use and Management 23, 16-24. doi:10.1111/j.1475-2743.2007.00108.x

Cook PG, Herczeg AL, McEwan KL (2001) Groundwater recharge and stream baseflow: Atherton Tablelands, Queensland. CSIRO Land and Water Technical Report 08/01, April 2001, Canberra, ACT.

Cotching B (1995) Long-term management of Krasnozems in Australia. Australian. Journal of Soil and Water Conservation 8, 18-27.

Gillman GP, Sinclair DF (1987) The grouping of soils with similar charge properties as a base for agrotechnology transfer. Australian Journal of Soil Research 25, 275-285. doi:10.1071/SR9870275

Holford ICR, Patrick WH (1979) Effects of reduction and pH changes on phosphate sorption and mobility in acid soil. Soil Science Society of America Journal 43, 292-297.

Hussain N, Church TM, Kim G (1999) Use of 222Rn and 226Ra to trace groundwater discharge into the Chesapeake Bay. Marine Chemistry $\mathbf{6 5}$, 127-134. doi:10.1016/S0304-4203(99)00015-8

Johannes RE (1980) The ecological significance of submarine discharge of groundwater. Marine Ecology Progress Series 3, 365-373. doi:10.3354/ meps003365

Johnson DW, Cole DW (1977) Anion mobility in soils: relevance to nutrient transport from terrestrial to aquatic ecosystems. Report EPA-600/3-77.

Koop K, Booth D, Broadbent A, Brodie J, Bucher D, Capone D, Coll J, Dennison W, Erdmann M, Harrison P, Hoegh-Guldberg O, Hutchings P, Jones GB, Larkum AWD, O’Neil J, Steven A, Tentori E, Ward S, Williamson J, Yellowlees D (2001) ENCORE: The effect of nutrient enrichment of coral reefs. Synthesis of results and conclusions. Marine Pollution Bulletin 42, 91-120. doi:10.1016/S0025-326X(00)00181-8

Lemola R, Turtola E (2000) Undersowing Italian ryegrass diminishes nitrogen leaching from spring barley. Agricultural Food Science Finland 9, 201-215.
Macpherson GL, Sophocleous M (2004) Fast groundwater mixing and basal recharge in an unconfined aquifer, alluvial aquifer, Konza LTER site, Northeastren Kansas. Journal of Hydrology 286, 271-299. doi:10.1016/ j.jhydrol.2003.09.016

Moody PW, Reghenzani JR, Armour JD, Prove BG, McShane TJ (1996) Nutrient balances and transport at farm scale - Johnstone River Catchment. In 'Downstream effects of land use'. (Eds HM Hunter, GE Eyles, G Rayment) (Department of Natural Resources: Brisbane, Q1d)

Moore WS (1999) The subterranean estuary: a reaction zone of groundwater and sea water. Marine Chemistry 65, 111-125. doi:10.1016/S0304-4203 (99)00014-6

Parker JM, Young CP, Chilton P (1991) Rural and agricultural pollution of groundwater. In 'Applied groundwater hydrology'. (Ed. WB Wilkinson) (Clarendon Press: Oxford, UK)

Rasiah V, Armour JD, Cogle AL (2005) Assessment of variables controlling nitrate dynamics in groundwater: is it a threat to surface aquatic ecosystems? Marine Pollution Bulletin 51, 60-69. doi:10.1016/ j.marpolbul.2004.10.024

Rasiah V, Armour JD, Cogle AL (2007) Statistical characterisation of impact of system variables on temporal dynamics of groundwater in highly weathered regoliths. Journal of Hydrological Processes 21, 2435-2446. doi:10.1002/hyp.6404

Rasiah V, Armour JD, Menzies NW, Heiner DH, Donn MJ, Mahendrarajah S (2003b) Nitrate retention under sugarcane in wet tropical Queensland deep soil profiles. Australian Journal of Soil Research 41, 1145-1161. doi:10.1071/SR02076

Rasiah V, Armour JD, Moody PW, Pattison AB, Lindsay S (2009) Characterising and improving the deteriorating trends in soil physical quality under banana. Australian Journal of Soil Research 47, 574-584. doi:10.1071/SR08256

Rasiah V, Armour JD, Yamamoto T, Mahendrarajah S, Heiner DH (2003a) Nitrate dynamics in shallow groundwater and the potential for transport to off-site water bodies. Water, Air, and Soil Pollution 147, 183-202. doi:10.1023/A:1024529017142

Rutkowski CM Jr, Burnett WC, Iverson RL, Chanton JP (1999) The effect of groundwater seepage on nutrient delivery and seagrass distribution in the north eastern Gulf of Mexico. Estuaries 22, 1033-1040. doi:10.2307/ 1353081

SAS (1991) 'SAS/STAT procedure guide for personal computers, Version 5.' (Statistical Analysis Systems Institute Inc.: Cary, NC)

Stieglitz TC (2005) Submarine groundwater discharge into the near-shore zone of the Great Barrier Reef, Australia. Marine Pollution Bulletin 51, 51-59. doi:10.1016/j.marpolbul.2004.10.055

Vinten AJA, Vivian BJ, Wright F, Howard RS (1994) A comparative study of nitrate leaching from the soils of differing textures under similar climatic and cropping conditions. Journal of Hydrology 159, 197-213. doi:10.1016/0022-1694(94)90256-9

Von Asmuth JR, Knotters M (2004) Characterising groundwater dynamics based on a system identification approach. Journal of Hydrology 296, 118-134. doi:10.1016/j.jhydrol.2004.03.015

Wivstad M, Dahlin AS, Grant C (2005) Perspectives on nutrient management in arable farming systems. Soil Use and Management 21, 113-121.

Yimprasert S, Belvins RL, Chaewsamoot S (1976) Movement of nitrate, chloride and potassium in a sandy loam soil. Plant and Soil 45, 227-234. doi:10.1007/BF00011144 